\title{
UPAYA MEMPERTAHANKAN ERGONOMIK PADA POSISI TUBUH SERTA PENCEGAHAN DAN MEMINIMALKAN RESIKO HAZARD PSIKOSOSIAL DALAM TINDAKAN KEPERAWATAN
}

\author{
Elisa Widyawati \\ elisawidyawati10@gmail.com
}

\section{LATAR BELAKANG}

Ergonomik yaitu ilmu ayang mempelajari perilaku manusia dalam kaitannya dengan pekerjaan mereka. Ergonomik berasal dari kata Yunani ergon yang artinya kerja dan nomos yang berarti aturan, secara keseluruhan ergonomik berarti aturan yang berkaitan dengan kerja, sasaran penelitian ergonomik adalah manusia pada saat bekerja dalam lingkungannya. Secara singkat dapat dikatakan bahwa ergonomik ialah penyesuaian tugas pekerjaan dengan kondisi tubuh manusia dengan tujuan untuk menurunkan stress yang akan dihadapi, yaitu dengan cara menyesuaikan ukuran tempat kerja dengan dimensi tubuh agar tidak melelahkan, pengaturan suhu, cahaya dan kelembaban betujuan agar sesuai dengankebutuhan tubuh manusia. Pengetahuan ergonomi membantu perawat menghindari faktor risiko tertentu yang berkontribusi pada gangguan muskuloskeletal dan meningkatkan keselamatan dan kesehatan di tempat kerja. Pengetahuan ergonomi memengaruhi sikap kerja saat melakukan tindakan keperawatan. Pendidikan dan pelatihan ergonomi perlu dilakukan untuk meningkatkan pengetahuan perawat tentang sikap kerja yang benar, Latihan peregangan dan penguatan yang tepat dan melaksanakan program aerobic progresif untuk meningkatkan kebugaran tubuh secara menyeluruh.

Bahaya psikososial kerja dapat didefinisikan sebagai aspek dari desain kerja,organisasi kerja dan manajemen kerja, serta segala aspek yang behubungan denganlingkungan sosial kerja yang berpotensi dapat menyebabkan gangguan pada psikologidan fisik. Potensi bahaya psikososial (psychosocial hazard) menurut definisidari International Labour Organization (ILO, 1986) mempunyai pengertian interaksiantara job content, organisasi kerja dan manajemen, dan keadaan lingkungan sertaorganisasi dari satu pihak dan kompetensi serta kebutuhan pekerja di pihak lain.Interaksi itu terbukti mempunyai pengaruh yang berbahaya terhadap kesehatan 
pekejamelaui persepsi dan pengalaman pekerja. Salah satu bahaya yang ada ditempat kerja adalah bahaya psikososial. Upaya pencegahan dan pengendalian bahaya kerjayang dapat menyebabkan terjadinya kecelakaan dan penyakit akibat kerja dapat dilakukan dengan penerapan keselamatan dan kesehatan kerja di tempat kerja. Salah satu hazard atau bahaya yang dapat terjadi dalam lingkungan pekerjaan adalah psikososial para pekerjanya. Dikarenakan hal tersebut upaya atau pencegahan pada hazard psikososial yangakan dibahas ini menjadi hal penting selain melindungi atau mencegah bahaya fisik atau luar lainnya. Dengan demikian untuk mewujudkan K3 perlu dilaksanakan dengan perencanaan dan pertimbangan yang tepat, dan salah satu kunci keberhasilannya terletak pada peran serta pekerja sendiri baik sebagai subyek maupun obyek perlindungan dimaksud dengan memperhatikan banyaknya risiko yang diperoleh.

\section{METODE}

Upaya mempertahankan ergonomic pada posisi tubuh serta meminimalkan resiko hazard psikososial dalam tindakan keperawatan, yakni teknik pengumpulan data dari berbagai sumber seperti textbook dan jurnal untuk mendapatkan data dan informasi yang lengkap dengan cara menyimpulkan dari 10 jurnal dengan tahun paling tua 2012. Dengan mencari dari berbagai jurnal maupun textbook dapat mudah dipahami dan dimengerti serta menyimpulkan nya dengan bahasa sendiri tanpa harus meniru karya orang lain.

\section{HASIL}

Penerapan Ergonomi di tempat kerja bertujuan agar pekerja saat bekerja selalu dalam keadaan sehat, nyaman, selamat, produktif dan sejahtera. Untuk dapat mencapai tujuan tersebut, perlu kemauan, kemampuan dan kerjasama yang baik dari semua pihak. Pihak pemerintah dalam hal ini Departemen Kesehatan sebagai lembaga yang bertanggungjawab terhadap kesehatan masyarakat, membuat berbagai peraturan, petunjuk teknis dan pedoman K3 di Tempat Kerja serta menjalin kerjasama lintas program maupun lintas sektor terkait dalam pembinaannya.

Ergonomi menjadi pilar kesehatan dan menjadi salah satu indikator kesejahteraan. Menurut Meily (2013), perbaikan ergonomi perlu dilakukan sebagai salah satu upaya pencegahan 
terhadap penyakit CTDs (Cumulative Trauma Disorders) akibat faktor risiko kerja postur janggal, beban, frekuensi dan durasi yang bersumber dari pekerjaan, seperti nyeri tengkuk, nyeri pinggang bawah atau low back pain, rasa baal pada jari telunjuk, jari tengah dan jari manis yang disertai nyeri terbakar pada malam hari, kekakuan, lemah dan nyeri saat tangan digunakan dan dikenal dengan nama Carpal Tunnel Syndrome.Dalam ergonomi, postur tubuh adalah faktor yang sangat penting, salah satunya postur duduk yang setiap orang lakukan setiap hari dalam durasi berjam-jam. Tujuan utama membuat desain ergonomi untuk kursi atau tempat duduk dan meja adalah menciptakan sedemikian rupa bentuk kursi dan meja belajar, sehingga dapat mempertahankan postur tulang punggung yang fi siologis, dengan demikian diharapkan kerja otot tidak perlu berkontraksi secara berlebihan (Meily, 2013).

Psikososial adalah hubungan antara kondisi sosial seseorang atau pekerja dengan kesehatan mental/emosionalnya. Hazard psikososial adalah suatu bentuk bahaya yangdapat mengancam kesehatan mental para pekerja dan risiko penurunan produktifitas pekerja. Dikarenakan hal tersebut upaya atau pencegahan pada hazard psikososial yang akan dibahas ini menjadi hal penting selain melindungi atau mencegah bahaya fisik atauluar lainnya. Dengan demikian untuk mewujudkan K3 perlu dilaksanakan dengan perencanaan dan pertimbangan yang tepat, dan salah satu kunci keberhasilannya terletak pada peran serta pekerja sendiri baik sebagai subyek maupun obyek perlindungan dimaksud dengan memperhatikan banyaknya risiko yang diperoleh.

\section{PEMBAHASAN}

Ergonomik yaitu ilmu ayang mempelajari perilaku manusia dalam kaitannya dengan pekerjaan mereka. Ergonomik berasal dari kata Yunani ergon yang artinya kerja dan nomos yang berarti aturan, secara keseluruhan ergonomik berarti aturan yangberkaitan dengan kerja, sasaran penelitian ergonomik adalah manusia pada saat bekerjadalam lingkungannya. Secara singkat dapat dikatakan bahwa ergonomik ialahpenyesuaian tugas pekerjaan dengan kondisi tubuh manusia dengan tujuan untukmenurunkan stress yang akan dihadapi, yaitu dengan cara menyesuaikan ukuran tempatkerja dengan dimensi tubuh agar tidak melelahkan, pengaturan suhu, cahaya dankelembaban betujuan agar sesuai dengankebutuhan tubuh manusia. 
Berdasarkanpengertian tersebut dapat disimpulakan bahwa pusat dari ergonomik adalah manusia.Konsep ergonomik adalah berdasarkan kesadaran, keterbatasan kemampuandannkapabilitas manusia. Sehingga dalam usaha untuk mencegah cidera, meningkatkanproduktivitas, efisiensi dan kenyamanan dibutuhkan penyesuaian antara lingkungan kerja,pekerjaan dan manusia yang terlibat dengan pekerjaan tersebut.

Tujuan Ergonomi Pelaksanaan dan penerapan ergonomi di tempat kerja di mulai dari yang sederhana dan pada tingkat individual terlebih dahulu. Rancangan ergonomi akan dapat meningkatkan efisiensi, efektivitas dan produktivitas kerja, serta dapat menciptakan system serta lingkungan yang cocok, aman, nyaman dan sehat. Adapun tujuan penerapan ergonomic adalah sebagai berikut :

1. Meningkatkan kesejahteraan fisik dan mental dengan meniadakan beban kerja tambahan(fisik dan mental), mencegah penyakit akibat kerja, dan meningkatkan kepuasan kerja

2. Meningkatkan kesejahteraan social dengan jalan meningkatkan kualitas kontak sesame pekerja, pengorganisasian yang lebih baik dan menghidupkan system kebersamaan dalam tempat kerja.

3. Berkontribusi di dalam keseimbangan rasional antara aspek-aspek teknik, ekonomi, antropologi dan budaya dari sistem manusia-mesin untuk tujuan meningkatkan efisiensi sistem manusia-mesin.

Ruang Lingkup Ergonomi Ruang lingkup ergonomi sangat luas aspeknya, antara lain meliputi:

1. Tehnik

2. Fisik

3. Pengalaman psikis

4. Anatomi, utamanya yang berhubungan dengan kekuatan dan gerakan otot dan persendian 5. Sosiologi

6. Fisiologi, kaitanya dengan temperature tubuh, oxygen up take, dan aktifitas otot 
7. Desain, dll

Manfaat Ergonomi

1. Menurunnya angka kesakitan akibat kerja.

2. Menurunnya kecelakaan kerja.

3. Biaya pengobatan dan kompensasi berkurang.

4. Stress akibat kerja berkurang.

5. Produktivitas membaik.

6. Alur kerja bertambah baik.

7. Rasa aman karena bebas dari gangguan cedera.

8. Kepuasan kerja meningkat.

Prinsip-Prinsip Ergonomik yaitu bekerja dalam posisi atau postur normal, mengurangi beban berlebihan, menempatkan peralatan agar selalu berada dalam jangkauan, bekerja sesuai dengan ketinggian dimensi tubuh, mengurangi gerakan berulang dan berlebihan, meminimalisasi gerakan statis, meminimalisasikan titik berat, mencakup jarak ruang, menciptakan lingkungan kerja yang nyaman, melakukan gerakan, olahraga, dan peregangan saat bekerja, membuat agar display dan contoh mudah di mengerti, dan mengurangi stress.

Upaya mempertahankan Ergonomi adalah sebagai berikut

\section{Sikap Berbaring}

Posisi klien penting telentang (dorsal RACKBIKE — tergeletak di belakang), rawan (berbaring pada perut), Sims' (semi-rawan-berbaring di samping [biasanya kiri] — dengan atas lutut tertekuk), Fowler di (tergeletak di belakang, dengan kepala tinggi), lutut-dada atau genupectoral (berbaring di lutut, dengan dada beristirahat di tempat tidur), dorsal lithotomy (tergeletak di belakang, dengan kaki di sanggurdi), dan lateral (berbaring di samping). Posisi telentang dapat dimodifikasi dengan menekuk lutut dan menempatkan kaki datar di tempat tidur. Trendelenburg's (posisi kepala-down — berbaring dengan kepala lebih rendah dari kaki)- 
digunakan untuk mengobati sengatan, dengan mempromosikan aliran darah ke otak. Posisi ini juga digunakan untuk beberapa bagian dari postural drainase, untuk membantu mengeringkan sekresi dari segmen paru-paru.

\section{Sikap Duduk}

Tulang punggung merupakan bagian tubuh yang memiliki peranan sangat besar dalam menjaga kestabilan tubuh. sebagian besar aktivitas sehari-hari dapat dilakukan dalam posisi duduk, sehingga penting untuk mengetahui posisi tubuh saat duduk yang benar untuk menjaga kesehatan tulang punggung.

\section{Sikap Berdiri}

Ketika mengangkat, berjalan, atau melakukan kegiatan tubuh, keselarasan tubuh yang tepat penting untuk menjaga keseimbangan. Ketika tubuh seseorang di alignment yang benar, Semua otot bekerja sama untuk gerakan paling aman dan paling efisien, tanpa ketegangan otot. Peregangan tubuh setinggi mungkin menghasilkan keselarasan. Ini dapat dicapai melalui tepat postur. Ketika berdiri, berat badan sedikit ke depan dan didukung di bagian luar kaki. Sekali lagi, kepala tegak, punggung lurus, dan perut terselip in. (ingat bahwa klien tempat tidur harus di sekitar posisi yang sama sebagai jika dia berdiri.

\section{Sikap Berjalan}

Berjalan kaki adalah salah satu latihan fisik benturan ringan yang bermanfaat bagi kesehatan. Selain bisa memperbaiki suasana hati, berjalan kaki juga membantu mengatasi depresi. Penelitian menunjukkan bahwa tingkat obesitas di negara-negara yang penduduknya biasa berjalan kaki lebih rendah daripada negara-negara yang penduduknya mengandalkan mobil sebagai sarana transportasi.

Cara berjalan yang baik adalah:

1. Biasakan berjalan dengan tubuh yang tegak.

2. Gunakan otot betis, paha belakang, dan kuadrisep agar Anda bisa berjalan dengan baik. Gerakan berjalan yang efektif melibatkan hampir semua otot tungkai, bukan hanya satu. 
3. Tariklah kedua bahu sedikit ke belakang, tetapi biarkan tetap rileks. Saat berjalan, Anda akan lebih banyak mengandalkan otot kaki dan otot perut. Walau demikian, Anda harus tetap memperhatikan postur tubuh atas. Menarik bahu sedikit ke belakang dalam kondisi rileks akan banyak manfaatnya. Postur ini menjaga tubuh Anda agar tetap kuat dan stabil saat Anda meluruskan punggung dari leher sampai pinggul. Melakukan postur ini sambil menegakkan punggung dan mengangkat dagu akan mencegah ketegangan di punggung dan menghindari terjadinya cedera.

4. Ayunkan lengan selama Anda berjalan. Mengayunkan lengan adalah hal biasa bagi banyak orang. Biarkan kedua lengan tergantung ke bawah secara alami. Saat mulai berjalan, lengan Anda akan berayun sedikit. Semakin cepat Anda berjalan, semakin lebar ayunannya. Mengayunkan lengan adalah sesuatu yang alami ketika Anda berjalan.

\section{Cara Mengangkat beban}

1. Pemanasan : Sama halnya seperti olahraga yang mengharuskan pelakunya untuk pemanasan supaya terhindar dari cedera. Kemudian, jaga bagian kaki dalam posisi lebar atau terbuka. Tujuannya agar dapat menopang tubuh Anda saat mulai mengangkat barang. Posisi kaki harus kuat, sama halnya seperti posisi kuda-kuda dalam olahraga karate.

2. Jongkokan badan ke bawah, pastikan Anda membengkokan bagian pinggul dan lutut. Lipat satu kaki di depan dan lipat satu kaki lainnya di lantai, posisi ini biasa disebut half kneeling. Kondisikan posisi badan Anda agar selalu tegak karena dapat meluruskan tulang belakang. Angkat barang secara perlahan sambil meluruskan lutut dan pinggul Anda. Ketika mengangkat barang hindari gerakan memutar.

3. Angkat barang agar tetap dekat dengan bagian perut. Ketika mengganti arah, putar bagian pinggul terlebih dahulu kemudian bahu. Saat menurunkan badan jongkokan badan secara perlahan diikuti dengan bengkokan lutut dan pinggul.

4. Jangan gunakan pinggang Anda untuk mengangkat dan menurunkan barang. Sebagian besar cedera dikarenakan melakukan posisi membungkuk ketika mengambil barang. Posisi membungkuk dapat memberikan tekanan pada pinggang bagian bawah. 
Suardi R. (2005) menyatakan bahwa hazards adalah sesuatu yang berpotensi menjadi penyebab kerusakan. Ini dapat mencakup substansi, proses kerja, dan atau aspek lainnya dari lingkungan kerja. Menurut A.M. Sugeng Budiono, dalam artikelnya "hazards" yang sering disebut potensi bahaya merupakan sumber resiko yang potensial mengakibatkan kerugian baik material, lingkungan maupun manusia.Safety Engineer Career Engineer Career Workshop (2003) mendefinisikan Hazard sebagai kondisi fisik yang berpotensi menyebabkan kerugian/kecelakaan bagi manusia atau lingkungan.

Psikososial adalah hubungan antara kondisi sosial seseorang atau pekerja dengankesehatan mental/emosionalnya. Hazard psikososial adalah suatu bentuk bahaya yangdapat mengancam kesehatan mental para pekerja dan risiko penurunan produktifitas pekerja. Dikarenakan hal tersebut upaya atau pencegahan pada hazard psikososial yangakan dibahas ini menjadi hal penting selain melindungi atau mencegah bahaya fisik atauluar lainnya. Dengan demikian untuk mewujudkan K3 perlu dilaksanakan dengan perencanaan dan pertimbangan yang tepat, dan salah satu kunci keberhasilannya terletak pada peran serta pekerja sendiri baik sebagai subyek maupun obyek perlindungandimaksud dengan memperhatikan banyaknya risiko yang diperoleh. Salah satu hazard atau bahaya yang dapat terjadi dalam lingkungan pekerjaan adalah psikososial para pekerjanya. Terjadinya kecelakaan kerja tentu saja menjadi masalah yang besar bagikelangsungan suatu usaha. Kerugian yang diderita tidak hanya berupa kerugian materiyang cukup besar namun kehilangan sumber daya manusia merupakan kerugian yang sangat besar karena manusia adalah satu-satunya sumber daya yang tidak dapat digantikan oleh teknologi apapun. Upaya pencegahan dan pengendalian bahaya kerjayang dapat menyebabkan terjadinya kecelakaan dan penyakit akibat kerja dapatdilakukan dengan penerapan keselamatan dan kesehatan kerja di tempat kerja.

Bahaya psikososial :

- Komunikasi yang buruk dengan atasan maupun dengan rekan kerja

- Jam kerja yang panjang dan tidak adanya rotasi sift kerja

- Aturan perusahan yang tidak jelas

- Beban kerja yang berlebihan 
- Kurang lengkapnya peralatan kerja serta sarana dan fasilitas kerja

- Pengawasan kerja yang kurang memadai

- Tidak diikutsertakan dalam pengambilan keputusan

- Perkembangan karir

Potensi bahaya psikososial (psychosocial hazard) menurut definisidari International Labour Organization (ILO, 1986) mempunyai pengertian interaksiantara job content, organisasi kerja dan manajemen, dan keadaan lingkungan serta organisasi dari satu pihak dan kompetensi serta kebutuhan pekerja di pihak lain.Interaksi itu terbukti mempunyai pengaruh yang berbahaya terhadap kesehatan perkeja melalui persepsi dan pengalaman pekerja. Terpajan hazard psikososial dapat mempengaruhi kesehatan fisik dan mentaltidak secara langsung melalui pengalaman stress. Kesehatan mental yang burukdihubungkan dengan frustasi yang timbul karena tidak memperoleh kepuasan kerjaatau situasi kerja dimana tuntutan-tuntutan pekerjaan yang tidak cocok atau tidaksesuai pengetahuan dan keterampilan atau kompetensi perkerja atau kebutuhanmereka. Aspek dari hazard psikososial sendiri membahas 2 aspek yaitu job content (beban kerja,desain tugas,jadwal kerja, dan peralatan kerja ) dan job context (hubungan interpersonal,perkembangan karir serta kebijakan dan pengawasan).

Upaya pegendalian atau pencegahan bahaya resiko, terhadap stress kerja pada karyawan, kegelisahan, depresi, penghargaan diri yang kurang sampai meningkatnyagejala penyakit jantung.

1. Elimination adalah menghilangkan semua faktor risiko dari process kerja yangmenjadi sumber bahaya.

2. Substitution adalah Mengganti hal-hal yang mempunyai pengaruh berbahayaterhadap psikis dan fisik pekerja

3. Minimasi adalah Memperkecil kemungkina timbulnya bahaya

4. Engineering Control adalah pendekatan secara teknik misalnya : penilaiankinerja pekerja, 
5. Administrative Control adalah pengawasan terhadap keputusan atau peraturan- peraturan yang telah disepakati bersama.

6. Supervisi atau bertujuan untuk meningkatkan pemahaman pekerja sehinggafaktor resiko timbulnya bahaya dapat dikurangi

7. PPE atau APD : Sebagai pelindung antara pekerja dan hal-hal pencetus bahaya dengan pemahaman pekerja yang baik dan pendekatan diri terhadap lingkungan dan tuhannya.

Potensi bahaya yang berasal atau ditimbulkan oleh kondisi aspek-aspek psikologis ketenaga kerjaan yang kurang baik atau kurang mendapatkan perhatian seperti: penempatan tenaga kerja yang tidak sesuai dengan bakat, minat, kepribadian, motivasi, temperamen atau pendidikannya, sistem seleksi dan klasifikasi tenaga kerja yang tidak sesuai, kurangnya keterampilan tenaga kerja dalam melakukan pekerjaannya sebagai akibat kurangnya latihan kerja yang diperoleh, serta hubungan antara individu yang tidak harmoni dan tidak serasi dalam organisasi kerja. Kesemuanya tersebut akan menyebabkan terjadinya stress akibat kerja.

\section{PENUTUP}

Ergonomi adalah ilmu untuk menggali dan mengaplikasikan informasi-informasi mengenai perilaku manusia, kemampuan, keterbatasan dan karakteristik manusia lainnya untuk merancang peralatan, mesin, sistem, pekerjaan dan lingkungan untuk meningkatkan produktivitas, keselamatan, kenyamanan dan efektifitas pekerjaan manusia. Pusat dari ergonomi adalah manusia. Penerapan Ergonomi di tempat kerja bertujuan agar pekerja saat bekerja selalu dalam keadaan sehat, nyaman, selamat, produktif dan sejahtera. Untuk dapat mencapai tujuan tersebut, perlu kemauan, kemampuan dan kerjasama yang baik dari semua pihak. Pihak pemerintah dalam hal ini Departemen Kesehatan sebagai lembaga yang bertanggungjawab terhadap kesehatan masyarakat, membuat berbagai peraturan, petunjuk teknis dan pedoman K3 di Tempat Kerja serta menjalin kerjasama lintas program maupun lintas sektor terkait dalam pembinaannya

Hazard atau bahaya adalah segala sesuatu yang dapat menimbulkan kerugian. Dengan melaksanakan K3 akan terwujud perlindungan terhadap tenagakerja dari risiko kecelakaan kerja 
dan penyakit akibat kerja yang dapat terjadi padawaktu melakukan pekerjaan di tempat kerja. Dengan dilaksanakannya perlindungan diharapkan akan tercipta tempat kerja yang aman,nyaman,sehat dan tenaga kerjayang produktif, sehingga akan meningkatkan produktivitas kerja dan produktivitas perusahaan .K3 sangat besar peranannya dalam upaya meningkatkan produktivitas perusahaan, terutama dapat mencegah korban manusia. Potensi bahaya yang berasal atau ditimbulkan oleh kondisi aspek-aspek psikologis ketenaga kerjaan yang kurang baik atau kurang mendapatkan perhatian seperti: penempatan tenaga kerja yang tidak sesuai dengan bakat, minat, kepribadian, motivasi, temperamen atau pendidikannya, sistem seleksi dan klasifikasi tenaga kerja yang tidak sesuai, kurangnya keterampilan tenaga kerja dalam melakukan pekerjaannya sebagai akibat kurangnya latihan kerja yang diperoleh, serta hubungan antara individu yang tidak harmoni dan tidak serasi dalam organisasi kerja.

\section{DAFTAR PUSTAKA}

Andarini,Desheila.dkk. (2019). Identifikasi Bahaya Psikososial Pada Buruh Wanita Di Pabrik Karet. Jurnal Kesehatan, No.1.

Emilia Puspita. (2015). Gambaran Masalah Keperawatan Psikososial di Ruang Gayatri RS Marzuki Mahdi Bogor. Jurnal Keperawatan Jiwa. 162-167.

Fathi, A., \&Simamora, R. H. (2019, March). Investigating nurses' coping strategies in their workplace as an indicator of quality of nurses' life in Indonesia: a preliminary study. In IOP conference series: Earth and Environmental science (Vol. 248, No. 1, p. 012031). IOP Publishing.

Harahap, A.R. (2015). Usulan Perbaikan Sistem Kerja Menggunakan Pendekatan 10 Physical Ergonomics Principles Pada Industri Pembuatan Saka Tebu Di Nagari Bukit Batabuah, Kabupaten Agam, Sumatera Barat. Padang : Jurusan Teknik Industri, Fakultas Teknik, Universitas Andalas.

Ibrahim, H., Damayanti, D. S., Amansyah,M., \& Sunandar. (2017). Gambaran Penerapan Standar Manajemen Keselamatan dan Kesehatan Kerja Rumah Sakit di Rumah Sakit Umum Daerah Haji Makassar. Al-Sihah : Public Health Science Journal, 9(2), 160-173. 
Indragiri, Suzana.,Triesda Yuttya(.2018).Manajemen Risiko K3 Menggunakan Hazard Identification Risk Assement and Risk Control (HIRARC). Jurnal Kesehatan, Vol 9 (1).

K., Ni Guru, Putu Oka. (2018). Kajian Ergonomi Pada Tindakan Keperawatan di IRD RS Universitas Udayana, Badung, Bali. Jurnal Keperawatan Respati Yogyakarta, 5(3), 414- 419.

Nilamsari, N., Soebijanto., M,L,S., R, S, B.(2015).Proto Type Bangku Ergonomis Untuk Memperbaiki Posisi Duduk Siswa SMAN Di Kabupaten Gresik . Jurnal Ners, Vol. 10 No. 1 April 2015: 87-103.

Pratiwi, Nurhantari, Y., \& Budiharjo, S. (2019). Hazard Identification, Risk Assesment and Risk Control Serta Penerapan Risk Mapping pada Rumah Sakit Hewan Prof. Soeparwi Universitas Gadjah Mada. BKM. Journal of Community Medicine and Public Health, 35(2), 55-64.

Restuputri, D. P. (2015). Analisis Kecelakaan Kerja Dengan Menggunakan Metode Hazard and Operability Study (HAZOP). Jurnal Ilmiah Teknik Industri, 14(1).

Simamora, R. H. (2020). Learning of Patient Identification in Patient Safety Programs Through Clinical Preceptor Models. Medico Legal Update, 20(3), 553-556.

Tarwaka. (2012). Dasar-dasar Pengetahuan Ergonomi dan Ini Aplikasi di Tempat Kerja. Surakarta: Harapan Press. 